\title{
TEACHING ENGUSH WITH PICTURE BOOKS: CURRENT CHALLENGES AND POSSIBLE SOLUTIONS IN ENGLISH EDUCATION IN JAPAN
}

\author{
Arisa Kochiyama \\ Department of International Studies, Wayo Women's University \\ kochiyama@wayo.ac.jp
}

First draft received: 31 March 2016

Final proof received: 24 August 2016

Abstract
The council for revitalization of education has submitted a proposal to Prime Minister Shinzo Abe for
educational reforms to make English language courses compulsory in the fifth and sixth grades. The
majority of elementary school teachers are now worried and lacking in confidence to teach English, as
they feel they are ill-equipped for their new role as language instructors. According to Keith Schoch's
article Picture Books across the Curriculum, picture books deserve a place in the upper elementary and
middle school grades for a number of reasons: If chosen with consideration for the interests of the
students and used in ways that are appropriate for learners, picture books can provide valuable
opportunities of language-rich experiences and interactions. Thus, the present study firstly describes
and analyses some of the challenges facing English education in Japan by relating to its wider social
setting. Secondly, the study analyzes how teachers perceive they can promote language learning in
their EFL classrooms through the medium of picture books. Thirdly, the study discusses the merits of
using picture books in the upper elementary and middle school English education from the viewpoint of
English language learning, and then investigates topics and themes of a picture book which illuminate
some universal aspects of human condition.
Keywords: Intercultural communication, English as a second language, EFL classroom, language and
gender, children's literature in EFL learning, early education
To cite this paper (in APA style):
Kochiyama, A. (2016). Teaching English with picture books: Current challenges and possible solutions in
English education in Japan. International Journal of Education, $9(1), 37-43$. doi:
dx.doi.org/10.17509/ije.v9i1.3716

\section{INTRODUCTION}

\section{Challenges Facing Early English Education}

As a way of nurturing people who can play an active role amid intensifying international competition, the Education Rebuilding Implementation Council, a governmental panel on education reform headed by Waseda University President Kaoru Kamata, has suggested boosting English language education in elementary schools by making it an official subject for fifth and sixth graders. Since the 2011 academic year, a "foreign language activity" has become a required course at primary schools and now, fifth- and sixthgraders take English classes once a week, which has guaranteed 8 years of English education. Despite these national efforts to enhance the early English education, many teachers have difficulty in teaching English. According to the article "Enhanced English Education Sought in Japanese Elementary Schools" in the Japan Times, English has not been treated as an official subject, and it has been taught only once a week mostly by homeroom teachers who have not had proper training in the language. In other words, most of the teachers are failing to offer their students the academic content and practical experience necessary to provide high-quality English education.

According to a nationwide survey conducted on 1309 schools in December 2013 by the Eiken Foundation of Japan, more than 70 percent of elementary schools were experiencing difficulties teaching a "foreign language activity" class. 74 percent said there were issues that needed to be addressed. Eiken foundation officials claimed that teachers felt puzzled and burdened while also feeling a certain level of effectiveness in teaching English. They said there was a need for more efficient method of teaching. Upgrading English to an official subject would require more training for elementary school teachers by adopting a system to educate and evaluate them with certifications to teach English.

Learning Environment of Japanese EFL Students One of the biggest issues which accompany learning English in the EFL environment is that learners have limited exposure to English in daily life. Little opportunity to use English makes it hard for learners to find a reason to study the language; in other words, they are not motivated to study the target language (Otsuki and Takase 2012). Additionally, with the grammar-translation method, the most common approach adopted at secondary schools across Japan, learners are easy to lose motivation for studying English. In the grammar-translation method, the emphasis is put on translating English text into Japanese word by word, rather than appreciating the content of the text (Otsuki and Takase 2012). Namiko Abe, a Japanese language expert, pointed out the problems of English education Japanese are facing; one of the reasons that students cannot use English properly after the six years of English education is the instruction focusing on the skill of reading and writing because study of foreign languages has been mainly considered to obtain the knowledge from the literature of other countries. Another reason is that English textbooks used in secondary education have been 
screened by the Ministry of Education, which makes English language learning too confining.

Learning environmental specific to Japan shown above seems to have had the negative effect on English learners and provided the demotivating factors that affect secondary school students learning EFL.

\section{Picture Books}

In recent years, a number of researchers suggest authentic children's literature as an alternative to the traditional bottom-up approach to EFL. For example, Ghosn (2002) offered the following good reasons for using authentic children's literature; first, children's literature provides a motivating context for language learning since learners are naturally drawn to stories; second, literature can contribute to language learning as it presents natural language, language as its finest, and can thus foster vocabulary development in context; third, literature can function as a change agent; good literature deals with some aspects of the human condition, and can thus contribute to the emotional development of the learners and foster positive interpersonal and intercultural attitudes. Similarly, Ellis and Brewster (2002) suggested that using children's literature can help develop positive attitudes towards the foreign language, culture and language learning; using stories allows the teachers to introduce or revise new vocabulary and sentence structures by exposing the children to language in varied, memorable and familiar contexts, which will enrich their thinking and gradually enter their own speech. They also emphasize the importance of reading aloud by pointing out that listening to stories helps learners become aware of the rhythm, intonation, and pronunciation of language. Given these findings, a pilot study was conducted to investigate how teachers perceive teaching English with picture books.

\section{A Pilot Study on Using Picture Books to Teach English \\ Results}

The subjects of the study consisted of 18 Japanese secondary education teachers (5 male, 13 female) with Japanese as their first language. They teach English either in private schools or in public schools located in the center of Japan. First, the merits of English teaching with picture books were explained, then reading tasks of reading aloud, translation, and teachers' written feedback were provided for a consecutive 90 minute class. The purpose of the reading aloud is to allow teachers not only to learn the target language, but also to recognize the rhythm original to the picture books. The picture books used were Whoever You Are by Mem Fox, The Paper Bag Princess by Robert Munsch, and Cinderella: ReadAlong.

In order to investigate how the teachers perceived English teaching with picture books after the pilot lesson was conducted, 4 multiple choice questions and 2 open-ended questions were provided in Japanese. Below is the translated version of questions to which the teachers responded. The numbers in parentheses next to a question indicate the number of teachers who chose it.

(1) Are you interested in using picture books in your English class?
a. Yes, very much (8)
b. Yes, sometimes (8)
c. I'm not sure (2)
d. No, not much
e. No, not at all

(2) What kind of effect, do you think, can be expected if picture books are used in English classes?

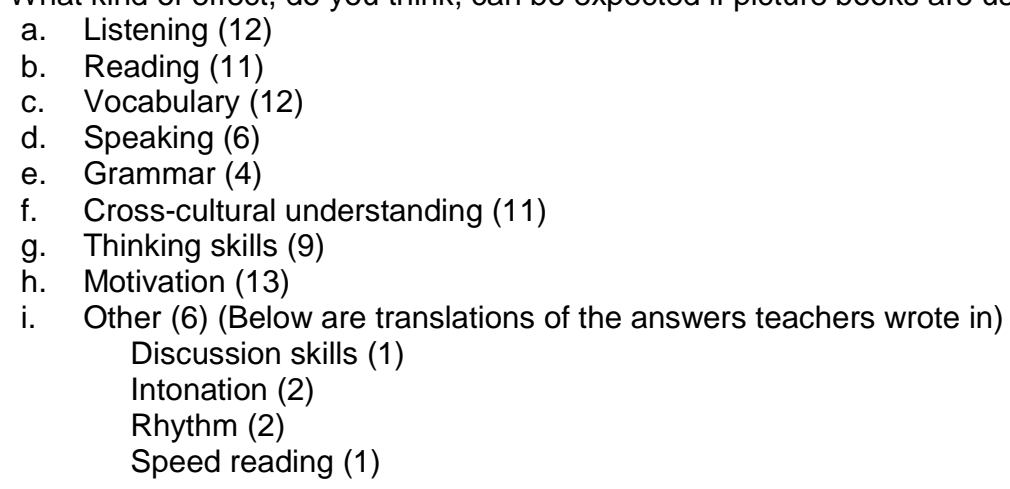

(3) What criteria would you use to select picture books for your English class?

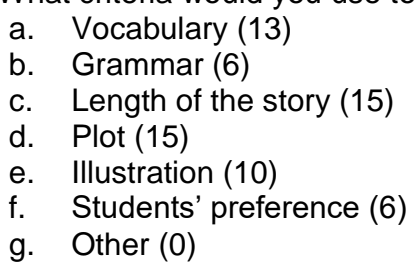

(4) What class (or classes) would you use if you use activities or tasks related to your English lesson through picture books?
a. English (14)
b. Moral education (9) 
c. Other (10) (Below are translations of the answers teachers wrote in)

Social studies (2)

Science (1)

Integrated study (4)

Homeroom activity (2)

Living environmental studies (1)

(5) To those who answered "English", "Moral education", or "Other". Why do you think so? (18) (Below are translations of the answers teachers wrote in)

English - It can be used in an Oral Introduction class.

It can help students to have discussion.

It can help students to write a new ending for the story.

Illustrations can motivate reluctant students.

Students can read the story without having any prejudice.

It is difficult to ask for help of non-English teachers.

The class can be conducted only in English.

Moral education - It can help foster positive interpersonal attitudes.

Students can think about human rights issues.

Students can think about the discrimination problem.

Students can think about gender issues.

It will help students to consider using English as a daily task.

Integrated studies - $\quad$ It can help foster international understanding.

It can help foster cross-cultural understanding.

Students can write a report on human rights issues in class.

Students can write a report.

Social studies - The story is closely related to social life.

Living environmental studies - It is something to do with interpersonal relationships.

Please specify the advantages of using picture books in an English class. (16)

(Below are translations of the answers teachers wrote in)

Students can be familiar with English pronunciation, intonation, and rhythm. (2)

Illustrations can improve the learning effect. (3)

Illustrations can help activate thinking on a visual level. (1)

Teachers can adopt it in place of the grammar-translation method. (1)

Students can relate the story to themselves. (1)

It can be adopted as one point lesson in class. (1)

It can help overcome students' English-phobia. (1)

It can motivate students to learn English. (5)

The class can be conducted only in English (1).

\section{Analysis}

Overall, the teachers had positive attitudes toward using picture books in their English classes, as 16 teachers said they were interested in using picture books in their classes and two said they were not sure. 13 teachers answered using picture books in English classes could enhance "motivation"; 12 answered "listening" and "vocabulary"; 11 answered "reading" and "cross-cultural understanding"; and nine answered "critical thinking skills." Speaking and grammar skills were also considered to be enhanced by some of the teachers. Write-in answers included "discussion skills", "intonation", and "rhythm". Thus, the teachers appear to think picture books deserve a place in English education not only because it enhances language learning, but also it can foster cross-cultural understanding and critical thinking skills. When selecting books, 15 teachers thought they should focus on length of the story and plot. 13 teachers answered "vocabulary"; 10 answered "illustration"; and 6 answered "grammar" and "students' preference". The teachers' responses indicate that some of the issues to take into account are the students' interest, enthusiasm, and motivation for the book. Another critical consideration appears to be the book's ability to meet learning objectives linked to reading, vocabulary, and grammar. In terms of the way to use picture books, 14 teachers thought it was appropriate to use them in English classes. Write-in answers indicate the possibility for reading-related activities that can promote speaking, writing, and critical thinking skills. Nine teachers thought it's appropriate to use picture books in their moral education classes in which students think about social issues related to the themes depicted in the books such as human rights, discrimination, and gender. For the similar reasons, four teachers suggested picture books be used in moral education classes. In addition, classes of social studies, living environmental studies, and science, and homeroom activities are suggested to be effective for adopting picture books.

\section{Merits of Using Picture Books Language Learning}

In his article "Picture Books across the Curriculum", Keith Schoch introduced fifteen reasons why picture books are useful for the daily curriculum of junior high 
schools. Among them are that they help build reading comprehension and provide succinct writing models for student writing. Since picture books tie ideas and vocabulary to illustrations, readers can define unknown words through context clues easily. In addition, as picture books waste little time, space, and words, individual sentences and paragraphs can be pulled from context in order to examine the author's craft without losing an overall sense of the text's content (Schoch n.d.).

It has been widely accepted in the EFL teaching context that input plays more important role than output. According to Krashen's (1981) Input Hypothesis, an essential factor for language acquisition is input that is comprehensible but that also contains language structures beyond the learner's current proficiency level. In addition, he claims that the input hypothesis has been successfully applied in the area of reading. Muranoi (2006) discussed four points to facilitate learners' second language learning: (a) Comprehensible input, where second language learners acquire the language by hearing and understanding messages that are slightly above their current target language level; (b) Relevance, in which texts should contain language forms and cultures relevant to learners to match the learners' interest; (c) Authenticity, in that input should be culturally and linguistically authentic, which provides the natural use of certain essential grammatical feature in communication; and (d) Auralwritten input, in which written and aural input should be well combined.

Keeping in mind the length and the level of difficulty as well as the students' interest in the context, a picture book titled Oliver Button Is a Sissy was used in the present study. The book has been selected because (1) it is written in simplified beginning-level English which parallels the language competence of a local junior high school graduate; (2) it tells interesting, sophisticated and critical story that learners of all ages can enjoy; and (3) it contains colorful illustrations, which can be great motivators for struggling or reluctant readers. In fact, Oliver Button Is a Sissy written and illustrated by an American author Tomie dePaola is a children's book whose story confronts gender stereotypes and importance of accepting people for who they are. Although children's literature, such as picture books, chapter books, and fairy tales, is commonly used in the reading practices in ESL/EFL classrooms, many researchers point out that gender bias is still prevalent in contemporary children's and young adult literature (Kuo, 2005). As a result, teachers need to be sensitive to their materials, or they will easily fall in to a passive acceptance of everything literature presents to us (Fox, 1993). Reading Oliver Button Is a Sissy is likely to empower students with critical thinking and alternative reading while improving their literacy.

In terms of the level of difficulty of Oliver Button Is a Sissy, the learners need 260 words to read the text. Since Japanese junior high school students have learned 900 English words, junior high school graduates can understand the overall meanings of the text using the thirty percent of the knowledge of English vocabulary. In terms of the grammatical features, the text includes the majority of grammatical items that are suggested for junior high school students to be learned, which are stated in the guideline made by the Japanese Ministry of Education, Culture, Sports, Science and Technology. The tenses used in the text include present tense, present progressive, past tense, past progressive, and simple future tense. Sentence structures used in the text include affirmative sentences, negative sentences, interrogative sentences, imperative sentences, and comparison. To-infinitives, passive voices, past particles, auxiliary verbs and gerund are used as well. Examples of each grammatical items appeared in the text are as follows:

Present

"I walk in the woods, I play jump rope, and I love to dance."

Present Progressive

"Never mind," said Papa, "we are taking our great dancer out for a great pizza. I'm so proud of you."

Past

He liked to read books and draw pictures.

Negative (Past)

He didn't like to do things that boys are supposed to do.

Interrogative

"What are those shiny shoes, sissy?" they said.

Imperative

"Don't be such a sissy! Go out and play baseball or football or basketball. Any kind of ball!"

\section{Comparison}

And he was always the last person picked for any team.

Past participle

And he was always the last person picked for any team.

To-infinitive

The master of ceremonies began to announce the prizes.

Passive Voice (Past)

Oliver Button was called a sissy. 
Simple Future

"I hope you will all go and cheer for Liver Button."

Auxiliary Verb

He would go up to the attic and put on costumes.

Gerund

But Oliver Button kept on going to Ms. Leah's Dancing School every week, and he practiced and practiced.

In the text, there appears to be a variety of repetitions of vocabulary, idioms, and expressions which enable learners to read similar or same words and grammatical structures over and over without noticing them and develop both grammatical and communicative competence. Rivers (1968) pointed out the effectiveness of pattern drills on foreign language learning, discussing that habits are strengthened by reinforcement, and analogy provides a better foundation for foreign language learning than analysis.

\author{
Repetition \\ "Dum-de-dum," the music went. \\ "Dum-de-dum-de-dum." \\ Oliver tapped and tapped. \\ "Dum-de-dum-de-dum-dum-DUM." \\ Oliver bowed, and the audience \\ clapped and clapped.
}

He didn't like to do things that boys are supposed to do.

He liked to read books and draw pictures.

He even liked to play with paper dolls.

And Oliver Button liked to play dress-up.

Examples above are repetitions of words and phrases shown in the text. According to Gannon (1987) who has investigated the merits of picture books in English education, repetition is one of the most familiar features of children's literature. Repetition not only adds rhythm and the mysterious charm of ritual to the simplest verbal formulas but clarifies the structure of narrative for young readers and helps them to remember what they have read.

Given the above findings, it is likely that Oliver Button Is a Sissy has the immense potential as a language learning tool in classrooms from the viewpoint of Input Hypothesis.

\section{Universal Themes}

Picture books whose story depicts universal themes can help students connect the character's values and attitudes to their own lives, which makes learning meaningful (Ghosn, 2002). Children's literature, including picture books, is often immediately relevant and motivating to readers since it addresses topics and themes of interest to readers and takes also into consideration their development needs. Children's books which illuminate some universal aspects of the human condition such as friendship, happiness, sadness, exclusion, courage, and so on enable readers to make meaningful connections (Ghosn, 2013). Ghosn further discussed that in a second language class, such texts will also function as agents of socialization through which learners can explore the values and standards of the target language culture and relate them to those in their own community.

Oliver Button Is a Sissy mentioned above is a good example that represents a variety of universal themes, as it depicts the story of a boy who stands up to bullies not by fighting but by staying true to himself. The story features the theme of accepting and remaining true to oneself even against expectations of the mainstream. Readers can explore discrimination and bullying, as Oliver is constantly teased and called "sissy" by his classmates. The ability to cope with stressful situations is also addressed in Oliver's behavior. Another frequent theme of overcoming fears is also described in the story as Oliver increases his practice time of dance lessons in hopes of winning the big talent show. In the end of the story, it reveals that the bullies' prejudices diminish when they get to know Oliver, as he discovers that someone has crossed out the word "sissy" on the school wall and added a new word that reads, "Oliver Button is a star!" Below is a lesson plan of theme-based reading suggested by Katy Byrns in her article "Lesson: Theme in picture books", which might be incorporated in the curriculum.

Table 1. Lesson Plans

\begin{tabular}{ll}
\hline LESSON PLAN TEMPLATE & LESSON PLAN \\
\hline Standard : RL 3.4 & $\begin{array}{l}\text { Narrative Analysis of Grade-Level-Appropriate Text: Understand that theme } \\
\text { refers to the meaning or moral of a selection and recognize themes (whether } \\
\text { implied or stated directly) in sample works. }\end{array}$ \\
\hline I. Desired Outcome & $\begin{array}{l}\text { By the end of the period, students will work in groups of } 4 \text { to identify the author's } \\
\text { message of at least } 2 \text { different picture books and give an example of that lesson } \\
\text { from the book and their own lives. }\end{array}$ \\
\hline II. Evidence of Learning & $\begin{array}{l}\text {-author's message grid } \\
\text {-share out in front of class }\end{array}$ \\
\hline
\end{tabular}

(Byrns, K. (n.d.). Theme in picture books. ERES Academy) 
Furthermore, discussing why what Oliver's classmates did was wrong and Oliver's choices will allow students to think critically about how boys are portrayed and compare these portrayals to their own lives. It is possible that the discussion of such a controversial issue led by the discussion questions can stimulate students to foster critical thinking and literacy and empower them with a future understanding of values and attitudes in their lives (Kuo, 2005). Critical thinking, according to Roch (2015), means thinking for yourself; it is the opposite of receiving information passively and looking at something from all sides and weighing up the evidence before adopting a particular stance or point of view. Roch further showed that critical thinking is a very empowering realization for children, as it is the idea that the teacher does not hold all the answers. In fact, the main goal of educators today is to teach students the skills they need to be critical thinkers. Instead of memorizing facts and ideas, students need to engage in higher levels of thinking to reach their fullest potential (Simon, 2014). Simon suggested that asking open-ended questions after reading a book can spark discussion, make them think critically, and encourage higher order thinking. Given the above arguments, Oliver Button Is a Sissy features themes and contents that are relevant to young learners and can provide a motivating and engaging medium for instruction.

\section{CONCLUSION}

The study investigated how teachers perceived teaching English with picture books and then argued that quality picture books would have a rightful place in teaching English to young learners. The use of picture books in the English language classroom has appeared to have several merits. First, picture books have the potential to develop language skills, especially vocabulary, grammar, and reading skills. Second, children's literature features themes and content that are relevant to young learners and addresses their concerns, fears and aspirations, and thus can provide a motivating and engaging medium for instruction (Ghosn, 2013). It has been discussed that appropriate follow-up activities, discussion or writing on theme-related topics led by teachers can enhance students' intercultural awareness and critical thinking skills. The carefully selected picture books may serve as an alternative to traditional EFL textbooks in reading classes because they give students opportunities to learn not only language skills but also some universal aspects of the human condition with which readers can make meaningful connections.

In order to better understand the benefits that picture books uniquely offer young EFL learners, further analysis of a number of aspects is required. It would be helpful to extend the study to examine the effect of illustrations on learners' comprehension and motivation for learning. In fact, the relationships of illustrations to print and to the child reader remain little understood (Elster and Simons, 1985; Schallert, 1980). As Meek (1995) noted, "The relation of pictures to stories and the nature of the reader's interaction with both are an important aspect of literacy too little regarded and even less understood". The second aspect to be investigated would be the effect of picture books on speaking. As shown above, the repetition, rhythm, and rhyme in picture books can allow learners to practice the sounds of language. Making read-alouds will promote learners' speaking ability. The third aspect of future research would be to compare how learners' language skills differ before and after class. By conducting pre- and post-tests to assess students' learning outcomes, the effect of using picture books on English language learning will become more apparent.

These are some of the avenues for future research on using picture books in the $E F L$ classroom. It is hoped that these studies and findings will contribute to shed light on improved approaches and methods for EFL teaching.

\section{REFERENCES}

Abe, N. (n.d.) The Japanese education systems: School life in Japan. About Education. Retrieved from

http://japanese.about.com/od/japaneselessons/a 1061000.htm.

Byrns, K. (n.d.). Theme in picture books. ERES Academy. Retrieved from http://betterlesson.com/community/lesson/3225/t heme-in-picture-books.

DePaola, T. (1979). Oliver Button is a sissy. New York: $\mathrm{HMH}$.

Disney Book Group. (2012). Cinderella read-along storybook and $C D$. New York: Disney Press.

Ellis, G. \& Brewster, J. (2002). Tell it again! The new storytelling handbook for primary teachers. Harlow: Pearson Education.

Elster, C. \& Simons, H. D. (1985). How important are illustrations in children's readers? The Reading Teacher, 39, 148-152. Enhanced English education sought in Japanese elementary schools. Retrieved from http://www.japantimes.co.jp/news/2013/05/16/na tional/enhanced-english-education-sought-injapanese-elementary-schools/\#.VeuJZWcx7IV

Fox, M. (1997). Whoever you are. New York: HMH.

Fox, M. (1993). Men who weep, boys who dance: The gender agenda between the lines in children's literature. Language Arts, 70, 84-88.

Ghosn, I. K. (2002). Four good reasons to use literature in primary school ELT. ELT journal, 56(2), 172-179.

Ghosn, I. K. (2013). Humanizing teaching English to young learners with children's literature. CLELE Journal, 1(1), 39-57.

Gannon, S. R. (1987). One more time: Approaches to repetition in children's literature. Children's Literature Association Quarterly, 12(1), 2-5.

Krashen, S. (1981). Second language acquisition and second language learning. Oxford: Pergamon.

Kuo, J. (2005). Teaching ESL/EFL student to recognize gender bias in children's literature. The Internet TESL Journal. Retrieved from http://iteslj.org/Articles/Kou-GenderBias.html

Meek, M. (1995). The critical challenge of the world in books for children. Children's Literature in Education, 26(1), 5-22.

Munsch, R. 2011. The paper bag princess. Toronto: Annick Press.

Muranoi, H. (2006). Effective English teaching and learning methods from the viewpoint of second language acquisition studies. Tokyo: Taishukan. 
Otsuki, K., \& Takase, A. (2012). Comparison of pedagogical grammar in picture books and English textbooks. Extensive Reading World Congress Proceedings, 1, 116-119.

Peterson, E. \& Coltrane, B. (2003). Culture in second language teaching. CAL Digest. Washington, DC: Center for Applied Linguistics. Retrieved from

http://www.cal.org/resources/digest/0309peterso n.html

Rivers, W. (1968). Teaching foreign language skills. Chicago: University of Chicago Press.

Roche, M. (2015). Developing children's critical thinking through picture books: A guide for primary and early years students and teachers. New York: Routledge.

Schallert, D.L. (1980). The role of illustrations in reading comprehension. In R. Spiro, B. Bruce, \& W. Brewer (Eds.), Theoretical Issues in Reading Comprehension (pp. 503-524). Hillsdale NJ: LEA.

Scholch, A. (n.d.). Picture books across the curriculum. Retrieved from http://teachingreadingandla.pbworks.com/f/Pictu re\%20Books\%20Across\%20the\%20Curriculum $\% 202011 \% 20$ revised.pdf

Shomberg, J. (1993). Messages of peace. Book Links, 3(1), 9-11.

Simon, C. A. (2014). How to encourage higher order thinking. International Reading Association. Retrieved from http://www.readwritethink.org/resources/resourc e-print.html?id=30624 